\title{
Research review on definition and support of small and medium-sized enterprises
}

\author{
Dongping $\mathrm{Yu}$ \\ International Business School \\ Yunnan University of Finance and Economics \\ Kunming, China \\ 247096657@qq.com \\ Xiangxue Lu* \\ International Business School \\ Yunnan University of Finance and Economics \\ Kunming, China \\ 1810842206@qq.com
}

\author{
Lifeng Wang \\ Nanchang Business College \\ Jiangxi Agricultural University \\ Nanchang, China \\ 258288164@qq.com \\ Guifeng Song \\ International Business School \\ Yunnan University of Finance and Economics \\ Kunming, China \\ 875563127@qq.com
}

\begin{abstract}
In the background of "One Belt and One Road" and "the setting up of the investment bank "will largely promote the development of small and medium-size enterprises in these areas. Small and medium-size enterprises support is a hot topic in the research field in recent years. Based on analysis of existing research, the paper summarized the definition, characteristics, development dilemmas and causes of small and medium-size enterprises; Then, classified systematically the main research results of small and medium-size enterprises support field; The results showed that: the academia puts too much emphasis on policy introduce, but overlooks the follow-up policy implementation, and lacks of empirical research. Finally, Future development about small and medium-size enterprises support was prospected accordingly.
\end{abstract}

Keywords-small and medium-size enterprises; development dilemma; policy implementation; empirical research; prospection

\section{INTRODUCTION}

As we all know, healthy and rapid development of small and medium-size enterprises (SMEs) will be able to contribute to economic growth, technological progress and social stability. However, the restriction of the human resource, capital, etc. severely hampered the development of SMEs. Since reform and opening up policy, the government has successively issued supportive policies to improve the plight of SMEs. Due to information asymmetry, severe non-market mechanism, etc. the operating environment of SMEs has been improved. But the problem of SMEs failed to be fundamentally solved. So far, the academic study of SME supporting has achieved fruitful results. However, the past research attaches great importance to the policy introduction but ignores the subsequent policy execution effect.

Based on the definition of the concepts and characteristics of SMEs, the paper analyzes the main difficulties and causes of SMEs' development. Then, the paper summarizes the research status by combing existing research and prospections for the future research to provide useful reference for future research.

\section{ThE DEFINITION OF SME}

\section{A. The definition of SME}

SME is a relative concept whose scale is smaller than large enterprises. We can divide the enterprises through three indexes---enterprise staff, sales figures and total assets. The division criterion of SME in China is based on the "SME promotion law the People's Republic of China". The relevant department under the state council formulates the standard according to the number of enterprise employees, sales, total assets combined with the characteristics of industry, and then submitted to the state council for approval. According to the current criteria: the number of employees in medium-sized enterprise and small-sized enterprise are 300-2000, 0-300; Sales are separately 30 million RMB - 300 million RMB; 0 RMB - 30 million RMB; Total assets are 40 million RMB400 million RMB, 0 RMB - 40 million RMB.

\section{B. The characteristics of SME}

1) Large quantity, wide range and small scale: Quantity of SMEs accounts for $99 \%$ of the total number of enterprises. Except for some special industries, SME is widely distributed in various industries, especially in agriculture, manufacturing, transportation, retail and service industry, etc.

2) Low technology, high labor intensity: Generally, SME is lack of manpower, fund and material resources. What's more, their profitability is weak, which lead to the insufficient of technology input fund. Therefore, SME can only rely on the input of a large amount of labor to product the low valueadded products.

3) Mainly for domestic market: Because of the small scale, less technology investment, finance difficulty, lacking access to information and poor ability on resist risks, products of SME lack of competitive and can't develop the international market.

\footnotetext{
*Corresponding author
} 
4) High production flexibility: Due to its small scale, management in SMEs is relatively concentrated. SMEs not only can quickly organize limited manpower, material resources and fund for production according to consumer's rapid changing demand, but also can quickly stop the production according to the declining demand of some kind of product.

\section{THE MAIN DIFFICULTIES AND THE CAUSES OF SMES}

\section{A. The financing difficulties}

The standard of equity financing is so high that SMEs can only rely on bank lending. However, the financial structure is imperfect and the construction of guarantee system is lagging behind in China. SMEs have the birth defects in scale and insufficient collateral. Together with the disadvantage of the opaque financial information and lack of credit record in the process of business, those problems lead to the financing difficulties of SMEs in China. The financing predicament is the bottleneck of SMEs' development. At present, the financing problem of SMEs in our country is mainly manifested in the following three aspects: 1) Insufficiency in own funds; 2) Single financing channel; 3) Higher financing costs.

\section{B. Rising costs lead to decreasing profits}

In recent years, due to the rising price and appreciation of the RMB, the price of raw materials has increased. In addition, many cities have increased the minimum wage standard, labor cost is soaring. Under double pressures, profit of SMEs was compressed seriously.

\section{The lack of high-quality people restricts enterprise's innovation ability}

As we all known, the treatment of employees is poor, the promotion mechanism unsound and the development prospect is not ideal in SMEs. In addition, the enterprise culture is weak and employees lack the sense of belonging within most SMEs. These reasons lead to serious brain drain in SMEs, which in return, restrict the improving of innovation ability.

\section{Unbearable enterprise tax}

As small-scale taxpayers, the tax burden on SMEs is generally higher in terms of the value-added tax and income tax. The phenomenon of arbitrary charges is widespread in the local government of China. Those increase the cost of SMEs and hinder their development.

\section{RESEARCH REVIEW ON THE EXECUTER OF SUPPORT POLICY FOR SMES}

Traditionally, it is the responsibility of government agencies to support SMEs. While $\mathrm{Wu}$ [1] thought the financing difficulty of SMEs results from the common failure of market mechanism and government regulation. Therefore, it is hard to solve the problem by market or government alone. Song and Jiang [2] thought except for the bank's financial exclusion, imperfect development of SMEs and macroeconomic failure are also important reasons of financing difficulties of SME. We need to combine government, financial institutions and SMEs to cope with the financial problem. Based on the principal-agent theory, Xiao and Xie [3] pointed out that the implementation of the financial support policies for the SMEs mainly relate to three interest subjects: the central government departments, local financial department and SMEs. After constructing three dynamic game mode, the equilibrium of benefit maximization has been calculated.

\section{RESEARCH REVIEW OF RESEARCH OF SUPPORTIVE POLICY FOR SMES}

SMEs play an irreplaceable role in national economic growth and social stability. However, the inherent defects result to SMEs' disadvantageous position in fierce market competition. These restrict the development of SMEs. In recent years, Chinese government has issued a series of supporting policies to promote the healthy and rapid development of SMEs, which produced positive effect in the operating environment of SMEs.

\section{A. The fiscal and taxation preferential policies}

Fiscal and taxation preferential policies for SMEs include SMEs financial preferential policies and tax preferential policies. Since the beginning of the opening up policy, the government fiscal and taxation support for SMEs has experienced four phases: discrimination, support and encouragement, preferential policy and scientific development The market position and operating environment of SMEs have significantly improved [4]. Tax preferential policies play a positive role in promoting SME's development. However, they come from different departments with diverse forms, and lack coordination, which result in imperfect preferential fiscal and taxation system [5]. In addition, the preferential policies have the disadvantage of poor pertinence and manipulation, which lead to unsatisfactory implementation effect [6].

\section{B. Financing support}

Academic circle doesn't reach an agreement on the proposition of large banks or small and medium-sized banks, which is more effective in solving the financing problems of SMEs. Xiao [7] argued that the financial system reform is necessary. We need to increase small and medium-sized financial institutions, break financial monopoly and promote the development of SMEs. However, Han [8] challenged this point of view. She points out that with the tilt of government policy, more obvious financial disintermediation manifestation, the enterprise credit environment has continuously improved. Together with banks' needs in new business, they gradually change the attitude to SMEs' financing. What's more, compared with the small and medium-sized banks, big banks have incomparable advantages in terms of business, therefore, the government should take further action to arouse the enthusiasm of big banks for SMEs financing.

\section{1) The construction of credit guarantee system}

In the academic circle, there has been a consensus on the positive role of loan guarantee agencies for the SMEs financing. But this mechanism, bank and SMEs would transfer risk to the guarantee agencies. Then, the guarantee agencies would cooperate with insurance company to spread 
risk. Among them, how to determine the ratio of risk sharing of SMEs financing among all the participants would be an inevitable problem. Xue and Wang [9] put forward a method for the above problems based on game theory perspective: setting up a risk-sharing mechanism which includes bank, guarantee agencies, insurance company and SMEs. This method tries to clear the responsibility of all the participants and arouses their enthusiasm. Through the analysis of the relation between risk and revenue among bank, guarantee agencies, insurance company and SMEs in the credit guarantee contract of SMEs, $\mathrm{Yu}$ and $\mathrm{Xu}$ [10] calculated the optimal proportion of risk allocation.

There has been a dispute on the selection of guarantee mode in academic circle. Wu [11] argued that in view of Chinese government's leading status in financial system and SMEs' running condition, the SMEs' guarantee mode should combine public and private. That is to say, government's policy guarantee mode is primary, collaborative guarantee mode of SMEs and commercial guarantee mode are adjuvant. $\mathrm{Li}$ [12] pointed out that compared with policy guarantee institution and commercial guarantee institution, this collaborative guarantee mode has advantages in the acquisition of enterprise information, reduction of financing cost, and the restriction of members' behavior, which should be primary mode of SMEs credit guarantee.

\section{2) The supply chain financing mode}

There are two main types of supply chain finance mode, -- dominated by core enterprise and the third party logistics enterprise. $\mathrm{Li}$ and $\mathrm{Liu}$ [13] built the evaluation system of SMEs financing mode by analytic hierarchy process (AHP) and comprehensively evaluated the traditional financing mode and supply chain finance mode. Conclusion showed that SMEs credit conditions get better, credit qualification gain promotion under the mode of supply chain finance, which ease the financial restraint of SMEs effectively. Based on neural fuzzy system, Fan et al. [14] built the rating mode of SMEs' credit risk under the supply chain financial mode, and verified the mode's validity by practical example, which provided reference for the assessment of SMEs' credit risk.

There has been a consensus on the positive role of supply chain finance for the SMEs financing in the academic circle. But there is a dispute on which mode is more effective. Ma et al. [15] argued that with the development of supply chain finance, the mode dominated by the third party logistics enterprises would become the primary mode of development in China in the future. Yao et al. [16] challenge this view and empirically tested the sample data. The results showed that the supply chain finance mode dominated by core enterprise can effectively relieve the SMEs' financing constraints, and the higher the degree of information asymmetry, the stronger the effect.

\section{3) Internet financial}

Internet financial, which mainly combines the Internet with the financial industry, is a new mode of carrying out financial business relying on the internet platform. The service pattern of Internet financial mainly includes ecommerce microfinance, P2P network credit, crowd-funding, etc. With strong ability to get and process data, internet financial and can effectively reduce the degree of information asymmetry between enterprises and SMEs, and the internet financial finish the loan process mainly relying on the Internet platform, which can greatly reduce the SMEs' financing costs [17]. But Liu [18] pointed out that Internet financial has eased the SMEs financing difficult to some extent but the information asymmetry still exists. He putted forward a new financing mode----“internet finance plus guarantee", in which guarantee agencies or insurance company would participate to share the risk. Moreover, although the relief effect of Internet financial mode for SMEs financing difficulty has been approved, the source of fund, the construction of customer credit system and the perfection of relevant laws restrict the further development of the Internet financial mode [19].

\section{4) SMEs clusters financing}

Industrial cluster is that a large number of enterprises with different rank and scale and collaboration relationship with each other cluster together in a specific industry in certain area. Based on industrial clusters, SME cluster financing is a new finance mode in which cluster overall qualification is the guarantee of SMEs finance. SMEs clusters financing have the advantage of relieving the degree of information asymmetry, and reducing the transaction costs and the risk of bank loans. Song and Yu [20] empirically studied the finance effect of clustered firms and no-clustered firms. Then, the result verified the positive role of cluster financing mode for SMEs financing difficulty.

The unique advantages of SME cluster financing mode have been recognized by academic circles. However, the problems in practice result in bad effect of SME cluster financing mode. Gao [21] drew lessons from foreign successful experience and suggested starting endogenous financial company within the cluster, which not only can embody the financing advantages, but also can satisfy the requirement of SMEs. Li [22] advocated establishing a mutual guarantee of SMEs within the cluster, which can further reduce the management risk of the bank. In addition, $\mathrm{Xu}$ and Chen [23] used the signaling game mode to tackle the trouble of converse choice. And Zhang [24] maintained that government should play its role in resolving SMEs financing difficulty by establishing government guiding fund to increase the fund supply. Jiang and Meng [25] pointed out that there are some technology or management risks with the existing SMEs financing models. In order to meet the cluster financing needs of SMEs in different development level. We can create two types of SMEs cluster financing modes------the early period and the mature period.

\section{5) The private financial}

The abundant folk capital and the improvement of credit guarantee system provide the necessity and feasibility for the development of folk financial [26]. Compared with the formal financial institutions, private finance mode is a financial activity among acquaintances, relatives or friends, which decides it has a natural connection with SMEs to ensure the information superiority of private financial. In addition, the private financial transaction procedure is simple, flexible, 
pertinent, which lower the transaction costs

The existence of the dual structure of financial market, lag regulation and higher interest rate in China lead to higher operating risk of private financial. Long [27] argued that Chinese government should strengthen the macro-economic control to regulate and guide the private financial in the supervision and management and the financial system. Chen [28] built the game strategy selection model under the trust mechanism and analyses the behavior of both sides of the deal of private financial business. The result showed that trust mechanism can improve the behavior of both sides of the deal, reduce the opportunism behavior, lower the financing cost, and improve the financing efficiency.

\section{Public service}

In recent years, the government has gradually established and perfected the SMEs public service system and carried out all-round, multi-level services for SMEs in the capital, technology, talents, information, management, et al, which greatly improve the operating environment for SMEs. In addition, the problem, whose domination of SMEs public service system can have higher efficiency, government or market, hasn't reached an agreement. Wang [29] pointed out that market failure is the root cause of SMEs dilemma. And he thought the construction of policy finance service system can effectively ease the financing difficulties of SMEs. However, based on the perspective of cooperation network approach of governance theory, Han et al. [30] advocated the market and social participation mechanism should be involved. And then the participation in public services system can realize the diversity and cooperative action to ensure the optimal efficiency of SMEs public service system. Fu and Mei [31] used data envelopment analysis (DEA) to evaluate the efficiency of two modes of SMEs public service platform, The result showed that the efficiency of public service platform dominated by market is higher than by government.

\section{Technology innovation}

The simplified structure, relaxed Work Environment, highly specialized product position and flexible business mode determine SMEs' unique advantages in the niche product innovation. However, the lack of capital, technology, human resource, et al, and SMEs' weak anti-risk ability restrict the technology innovation ability of SMEs. Feng [32] argued that technology innovation has the character of uncertainty, long periodicity, positive externalities, and high input, which determines the requirement of SMEs technology innovation is fiscal and taxation preferential policy of government. Because the market mechanism can't solve the problem of SMEs financing, instead the government's financial support can be a strong support. Li and Mei [33] thought the root cause of poor technology innovation ability is the poor behavior of intermediary agent of technological innovation service. Then, lessons should be drawn from foreign successful experience. We should establish and perfect the intermediary service system of technological innovation of SMEs and its market operation mechanism.

In addition, on the basis of internal incentive mechanism, $\mathrm{Li}$ [34] built the internal incentive mechanism of technological innovation of SMEs. And as for the selection of technology innovation mode of SMEs, Nian [35] advocated the imitation innovation. And choosing innovation objects and methods, the realizing the innovation process constitute the basic order of imitation innovation. After investigation and interview, Yin [36] constructed the technology innovation risk evaluation index system including 42 factors, which can evaluate the potential risks of the technological innovation project. Based on the grounded theory, Su and Song [37] summarized the driving factors for SMEs technology innovation through analysis of different cases and construct the driving factors mode of SMEs technology innovation. In order to evaluate the technology innovation ability of SMEs, Chen et al. [38] constructed the BP neural network mode on the basis of the theory of BP neural network and verify its validity.

Based on the above review, we can build the following figure 1 of support system for SMEs.

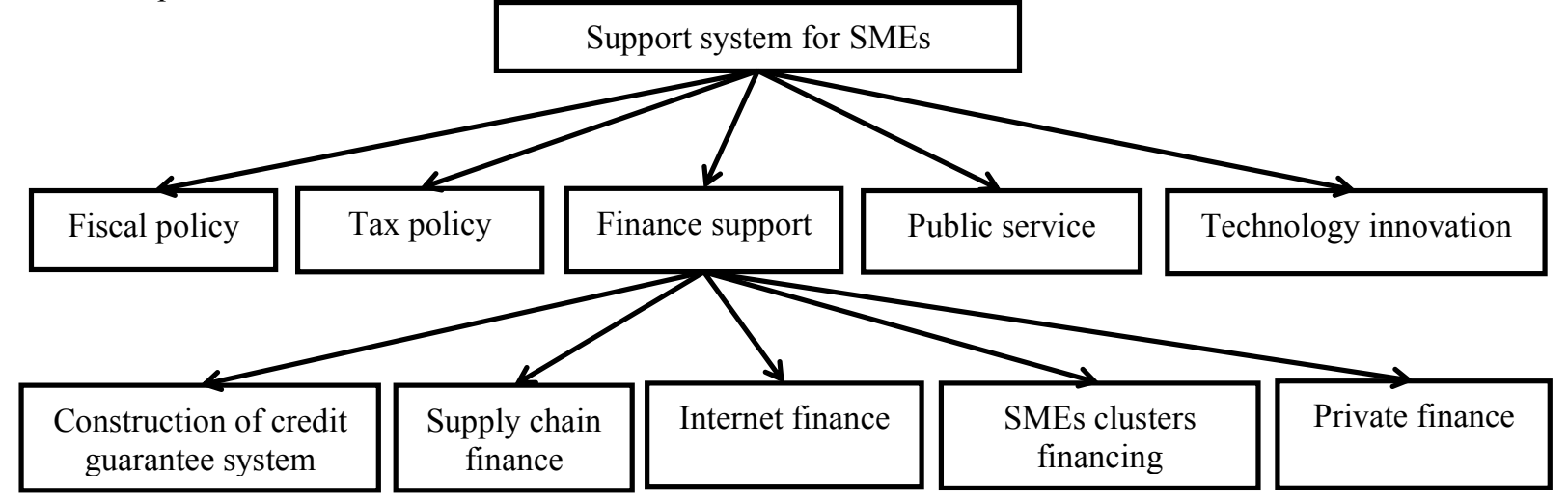

Fig. 1. The support system for SMEs

\section{CONCLUSIONS}

\section{A. The summary}

We may come to the following conclusions after reviewing the literature:

Government, SMEs and other social organizations are involved in every phase of supportive policies. Therefore, government, SMEs and social organizations should support 
each other and coordinate to ensure the effect of SMEs Supportive policies and achieve the aim of policy design. In addition, in the past, the scholars' research about SME support concentrated in fiscal and tax preferential policy, financing support, public services, and technology innovation. The previous research attached great importance to the policy introduction, despise policy execution effect, and lack empirical research. Finally, the research for measuring and improving execution efficiency is rare.

\section{B. The outlook}

To sum up, the following problems in SMEs support field need further study: 1) More efficient in easing SMEs financing constraints, support policies on small, medium-sized banks or the arouse enthusiasm of large banks? 2) The best choice of guarantee mode, policy guarantee mode of government, collaborative guarantee mode of SMEs or commercial guarantee mode? 3) More efficient supply chain finance mode, dominated by Core enterprise or the third party logistics enterprise? 4) Financing source of internet financial mode and the construction of customer credit system need to be further studied. 5) The study on function mechanism of SMEs cluster financing mode will be the future research direction. 6) The measurement and improvement of support policies effect, the perfection of SMEs information structure and the improvement of legal system need future study.

\section{ACKNOWLEDGMENT}

This work was supported by Key Programs of Education Department in Yunnan Province (the project number is 2013Z067), supported by Scientific Research Start-up Foundation for Talent Introduction of Yunnan University of Finance and Economics (the project number is YC2013D26), supported by Philosophy and Social Science Planning Program in Yunnan province, (the project number is YB2016064), and supported by Graduate Innovation Fund Project of Yunnan University of Finance and Economics (the project number is 2017YUFEYC020). Thanks for all the sponsors.

\section{REFERENCES}

[1] Q.C. Wu, "The debate of causes and solutions of SME financing difficulties------relying on the visible hand or the invisible hand", Financial Theory \& Practice, vol. 35, 2013, pp. 70-73.

[2] S.J. Song, and Y. He, "The causes and solutions of SME financing difficulties”, Jiangxi Social Sciences, vol. 34, 2013, pp. 219-222.

[3] N.T. Xiao, and C. Xie, "Three dynamic game model analysis of SMEs financial support policy in the Implementation", Public Finance Research, vol. 35, 2014, pp. 29-32.

[4] C. Liu, "The paradigm shift of the fiscal and taxation support policy for SMEs", Social Sciences in China, vol. 34, 2013, pp. 60-69.

[5] G.J. Jia, and Y. Tan, "Tax support policy of promoting the SMEs development in our country", Review of Economic Research, vol. 35, 2013, pp. 36-38.

[6] L.L. Jiang. "Research of SMEs tax preferential policy in our country under the new normal of Chinese economy Taxation and Economy", vol. 37,2015 , pp. 85-89

[7] J. Xiao, "Dose the development of small and medium-sized financial institutions ease the SMEs financing constraints? - - Based on the research of regional institutional environment differentiation", Finance Forum, vol. 21, 2016, pp. 58-70

[8] Y.X. Han, M. He, and H.M. Li, "Why big Banks help SMEs finance?-----Based on the case study of a major bank branch", Finance Forum, vol. 21,2016 , pp. $72-80$
[9] Y.X. Xue, D.C.Wang, "The study of risk sharing ratio of SMEs credi again guarantee agency",. Inner Mongolia Social Sciences, vol. 34, 2013, pp. 103-106.

[10] X.J. Yu, and W.J. Xu, "Each partner analysis of risk and benefit of SMEs credit again guarantee", Journal of Systems Science and Systems Engineering, vol. 22, 2013, pp. 33-39.

[11] M.X. Wu, "The experience and enlightenment of SMEs credit guarantee system from every country in the world for our country", World Economy Studies, vol. 33, 2014, pp. 16-21.

[12] Y. Li, "The choice and innovation of operating mechanism of SMEs credit guarantee institutions in our country", Journal of Wuhan University of Technology(Materials Science Edition), vol. 28, 2015, pp 929-935.

[13] S. Li, and Y.H. Liu, "the SMEs credit problems research from the point of view of supply chain financial-----the comparison and analyses on the basis of AHP”, Science \& Technology and Economy, vol. 26, 2013, pp. 61-65.

[14] L.B. Fan, J. Jia, and L. Jia, "The research of SME credit risk rating model under the finance mode of supply chain", Journal of International Economic Cooperation, vol. 30, 2014, pp. 90-94.

[15] J. Ma, J.Q. Wan, and X.Y. Shen, "SMEs financing innovation relying on the supply chain finance. Commercial Research”, vol. 56, 2013, pp. 131-137.

[16] W.X. Yao, J. Xia, and T.T. Sun, "The study of financing constraints and ease for SME of science and technology from the point of view of supply chain finance", Science \& Technology Progress and Policy, vol 34, 2017, pp. 105-110.

[17] P. Xiao, "Internet financial and resolving way of financing difficulties of SME", Journal of Henan Normal University (Philosophy and Socia Sciences Edition), vol. 56, 2015, pp. 77-80.

[18] J.Q. Liu, "The research of Internet finance and SME of science and technology financing", Academic Exploration, vol. 22, 2014, pp. 124 131.

[19] W.Q. Li, "Research of Internet financial solving SME financing problems", Academic Journal of Zhongzhou, vol. 36, 2014, pp. 51-54.

[20] H. Song, and K.K. Yu, "Research of external financing differences between clustered SMEs and no-clustered SMEs", Economic Management Journal, vol. 30, 2008, pp. 14-21.

[21] L.H. Gao, "SMEs cluster financing: mode innovation, financing boundary and competitive advantage", Comparative Economic \& Social Systems, vol. 23, 2007, pp. 92-97.

[22] R.X. Li. "Enterprise mutual guarantee and SMEs cluster financing----based on the perspective of relationship embedded", Taxation and Economy, vol. 31, 2009, pp. 47-51.

[23] L.F. Xu, and G.H. Chen, "SME financing analysis under Industry cluster on the basis of the signaling game", Chinese Journal of Management Science, vol. 20, 2012, pp. 74-78.

[24] J. Zhang, "Innovation research of SMEs cluster financing mode", Economic Review, vol. 28, 2012, PP. 124-127.

[25] Y. Jiang, and S. Meng, "SMEs cluster financing pattern analysis based on the risk control", The Journal of Shanghai Administration Institute, vol. 16, 2015, pp. 88-95.

[26] W. Li, C. Huang, and F. Jiang, "Develop folk finance in our country to solve the financing difficulties of SMEs", Journal of Shanghai Jiaotong University(Philosophy and Social Sciences), vol. 9, 2001, pp. 61-64.

[27] Z.H. Long, "The legal regulation of the private lending risk", Nanjing Journal of Social Sciences, vol. 25, 2014, pp. 81-88.

[28] S. Chen, "Study of the folk financial development under the perspective of trust", Productivity Research, vol. 29, 2014, pp. 44-46.

[29] Q. Wang, "The thinking of establishing the policy financial service system of SME in our country", Productivity Research, vol. 19, 2004, pp. 67-68.

[30] G.M. Han, S.G. Lv, and Z. Liu, "The diversity research of the governance subject of socialization service system for SME in our country------from the perspective of cooperation network approach of governance theory", Science and Technology Management Research, vol. 29,2009 , pp. 144-146. 
[31] X.F. Fu, and Q. Mei, "Efficiency analysis of SMEs public service platform in our country based on DEA", Science and Technology Management Research, vol. 32, 2012, pp. 66-69.

[32] X.J. Feng, "The research of fiscal and taxation policies promoting SME technology innovation", Science and Technology Management Research, vol. 30, 2010, pp. 54-56.

[33] W.Y. Li, and Q. Mei, "Construction research of science and technology intermediary service system based on the whole process of SME technology innovation", Forum on Science and Technology in China, vol. 25, 2009, pp. 59-63.

[34] Y. Li, "Research of the internal incentive mechanism of SME technology innovation", Scientific Management Research, vol. 23, 2005, pp. 13-16.

[35] Z.Y. Nian, "Selection of SME technology innovation mode----.imitation innovation", Scientific Management Research, vol. 24, 2004, pp. 19-21.

[36] Z.L. Yin, "Research of risk evaluation index system of SME technology innovation", Journal of Central University of Finance \& Economics, vol. 31, 2011, pp. 78-81

[37] J. Su, and Z.G. Song, "Research of the key driver factors of technology innovation for SME of science and technology------on the basis of an exploratory analysis of four companies from Beijing and tianjin", Science of Science and Management of S.\& T, vol. 35, 2014, pp. 156163.

[38] Z. Chen, D.L. Zhang, and M.Y Shan, "Evaluation research of technology innovation ability of SME based on the BP neural network", Science and Technology Management Research, vol. 30, 2010, pp. 5658. 